\title{
Next Generation Sequencing Technologies in Malaria
}

\section{Vathsala Palakkod Govindan ${ }^{*}$ and Krishna Murthy P}

Indian Institute of Science, Bangalore, Karnataka, India

*Corresponding author: Vathsala Palakkod Govindan, Undergraduate Programmer, Indian Institute of Science, Bangalore, Karnataka, India, Tel: +919900096434; Email: dr.vathsala2010@gmail.com

Rec date: Aug 23, 2016; Acc date: Nov 08, 2016; Pub date: Nov 10, 2016

Copyright: $\odot 2016$ Govindan VP, et al. This is an open-access article distributed under the terms of the creative commons attribution license, which permits unrestricted use, distribution, and reproduction in any medium, provided the original author and source are credited.

\begin{abstract}
The research outlook in life sciences is futuristic, thanks to next generation sequencing technologies. With regard to malaria research, use of next generation sequencing techniques, a tool of great value for study of various infectious diseases, have help find multidrug resistance cause of anti-malarial drugs. Earlier efforts toward sequencing of genes were laborious, expensive and time consuming. At present, advancement in the field of next generation sequencing technologies are changing the horizon and promising an era of elevated human health. In this mini review, the present and potential applications of next generation sequencing technologies in malaria research are discussed.
\end{abstract}

Keywords: Next generation sequencing; Malaria; Plasmodium; Drug resistance; Human health; Infectious diseases

\section{Introduction}

Malaria, an illness caused by protozoan parasites (Plasmodium) and transmitted by mosquitoes, is the main cause of death in children and pregnant women [1]. Most affected areas are underdeveloped countries with $60 \%$ mortality rate $[2,3]$. However, with several advancements in control and management of the disease, the deaths in children, worldwide, below the age of five have fallen by $47 \%$ to $54 \%$ since 2000 [4]. The species of parasites that causes malaria include $P$. falciparum, $P$. vivax, $P$. ovale and $P$. malariae. Of these, $P$. falciparum is widespread in affected regions and causes most deaths. In this regard, new technologies and ideas are explored in search of new treatments and vaccines against malaria. One such approach is whole genome sequencing and analysis of malaria parasites. As reported by Gardner et al. [5], sequence analysis of $P$. falciparum showed the parasite consists of a 23-megabase genome with 14 chromosomes, encoding approximately 5,300 genes with unusual complexity compared to other eukaryotic genomes. Two key unusual features of $P$. falciparum genome are AT-rich content $(82 \%)$ and poor correlation between the length of a gene and the functional domains of gene due to lack of intron splicing [6]. Owing to composition of genomes, polymorphisms and divergence in size, both within and different species of malaria, the current information of $P$. falciparum genome limits us from extrapolating to other species of malaria. Nevertheless, the rapid pace in developments of next generation sequencing technologies could help to solve this problem.

The most favoured and widely used approaches for sequencing are Maxam and Gilbert chemical degradation and Sanger dideoxynucleotide methods however, the techniques are not without constraints [7,8]. The biggest limitations are in terms of highthroughput, large-scale, efficient gene sequencing. With the growing technological advancements, techniques such as large-scale DNA sequencing without gels and reversible terminators were developed with focus on speed and efficiency [9]. On the same scale, platforms such as Illumina/Solexa, ABI/SOLiD, 454/Rochie and Helicos are in the forefront in providing unmatched possibilities for high-throughput genomic research. By generating five million base sequences in hours, 'Pyrosequencing' developed at 454 Life Sciences is one such example that shows the enormous advantage the platform provides for gene sequencing [10].

\section{Next Generation Sequencing Applications in Malaria}

Next generation sequencing (NGS) may overrule the Sanger method of sequencing and expected to advance and make the drug discovery process more rapid. The impact of next generation sequencing techniques in dealing with complex biological problems is huge. One such impact is seen in identification of the sequence changers in drug resistant malaria, HIV, Tuberculosis and cancer. Individual loci associated with drug resistance to many anti-malarials have been identified but their mechanisms have not been elucidated. In addition, NGS technology will create tremendous impact in medical sciences. Understanding of multiple non-genetic and genetic mechanisms of drug resistance would help us in efficient designing and pairing of future anti-malarials for clinical use.

Drug resistance remains a major public health challenge for malaria treatment and eradication. With the completion of malaria parasite genome sequencing, it has leads to greater understanding of the complex biological processes in malaria parasites. Recent technologies with NGS considers a "High-Throughput Technology" which is cost and exponentially effective with first, second generation HT-NGS and third generation sequencing [11-14]. At present, research is being increasingly focused on identifying multidrug resistant cause of antimalarial drugs by employing next generation sequencing techniques, which is of great value for infectious diseases such as malaria.

Whole genome shotgun sequencing of a clone (3D7) of $P$. falciparum has generated a wealth of information about its genome structure, proteome and metabolic potential of several predicted proteins [5]. Likewise, a series of initiatives have begun to generate data on other species of malaria [15], thereby, opening a path for drug resistance and gene discovery despite the huge divergence shown between the species. In addition, a single-cell genomics approach has been established for sequencing of malaria parasite genome sequences 
Page 2 of 2

directly from patients' blood, which led us to identify and understand drug resistance haplotypes from multiple genotype infections [16]. The variation in haplotypes can also been used to estimate the origin of parasites [17]. On the other hand, genome sequence data from $P$. falciparum have led to comparative studies in understanding characteristic biased amino acid composition of proteins of $P$. falciparum with other eukaryotes [18], which in turn could help understand the specificity of the disease and development of new drug targets.

Methodological advances in NGS such as sequencing by synthesis (SBS) [19], Polony sequencing [20], Nanopore sequencing, sequencing by hybridization $(\mathrm{SBH})$ and sequencing by ligation (SOLiD) $[21,22]$ in conjunction with advanced bioinformatics tools have been contributory to solving fundamental puzzles of drug discovery. NGS technologies in PiggyBac transposon system have helped the system to become a powerful tool in studying gene functions in malaria parasite [23]. The imputation of whole exome sequencing along with lower frequency analysis of variants in the population gives an opportunity to identify rare coding variations in complex traits of several diseases [24]. The new tools of gene expression of Plasmodium proteins measured directly from the tissue during human infection and metagenomic application of NGS by new culture independent detection of pathogens have lead to better understanding of the hostparasite interactions [25]; thus a powerful future application of NGS to combat malaria infections and restore health.

\section{Conclusion}

Enhanced platforms of NGS are the way forward for further understanding of malaria host-parasite interactions, vector biology and future prospects for the global elimination of malaria. Continued advances in technologies such as single-molecule sequencing and powerful bioinformatics tools to resolve mixed infections and the accurate, rapid response platform provided by NGS will become cornerstones of malaria infection control. In near future, we envision of clinical laboratory setups furnished with high performance genome sequencing platforms that would enable us to derive Plasmodium genomes by direct sequencing of clinical samples with automation to identify drug resistant malaria species. We need to look no further than the current challenges of drug resistance; malaria will never be a solved problem because of mimic played by the parasite rather only by substantial effect offered by NGS with the disease.

\section{References}

1. Aditya NP, Vathsala PG, Vieira V, Murthy RSR, Souto EB (2013) Advances in nanomedicines for malaria treatment. Adv Colloid Interface Sci 201-202: 1-17.

2. Korenromp EL, Williams BG, Gouws E, Dye C, Snow RW (2003) Measurement of trends in childhood malaria mortality in Africa: An assessment of progress toward targets based on verbal autopsy. Lancet Infect Dis 3: 349-358.

3. Snow RW, Guerra CA, Noor AM, Myint HY, Hay SI (2005) The global distribution of clinical episodes of Plasmodium falciparum malaria. Nature 434: 214-217.
4. Organization WH (2014) World Malaria Report 2014.

5. Gardner MJ, Hall N, Fung E, White O, Berriman M, et al. (2002) Genome sequence of the human malaria parasite Plasmodium falciparum. Nature 419: 498-511.

6. Forsdyke DR (2016) Evolutionary Bioinformatics. (3rdedn.) Springer.

7. Maxam AM, Gilbert W (1977) A new method for sequencing DNA. Proc Natl Acad Sci USA 74: 560-564.

8. Sanger F, Nicklen S, Coulson AR (1977) DNA sequencing with chainterminating inhibitors. Proc Natl Acad Sci USA 74: 5463-5467.

9. Ansorge WJ (1991) Next-generation DNA sequencing techniques. New Biotechnology 25: 195-203.

10. Margulies M, Egholm M, Altman WE, Attiya S, Bader JS, et al. (2005) Genome sequencing in microfabricated high-density picolitre reactors. Nature 437: 376-380.

11. Le Roch KG, Zhou Y, Blair PL, Grainger M, Moch JK, et al. (2003) Discovery of gene function by expression profiling of the malaria parasite life cycle. Science 301: 1503-1508.

12. Carlton JM, Adams JH, Silva JC, Bidwell SL, Lorenzi H, et al. (2008) Comparative genomics of the neglected human malaria parasite Plasmodium vivax. Nature 455: 757-763.

13. Dharia NV, Bright AT, Westenberger SJ, Barnes SW, Batalov S, et al. (2010) Whole-genome sequencing and microarray analysis of ex vivo Plasmodium vivax reveal selective pressure on putative drug resistance genes. Proc Natl Acad Sci USA 107: 20045-20050.

14. Khan SM, Franke-Fayard B, Mair GR, Lasonder E, Janse CJ, et al. (2005) Proteome analysis of separated male and female gametocytes reveals novel sex-specific Plasmodium biology. Cell 121: 675-687.

15. Carlton JM, Carucci DJ (2002) Rodent models of malaria in the genomics era. Trends Parasitol 18: 100-102.

16. Nair S, Nkhoma SC, Serre D, Zimmerman PA, Gorena K, et al. (2014) Single-cell genomics for dissection of complex malaria infections. Genome Res 24: 1028-1038.

17. Anderson TJC, Roper C (2005) The origins and spread of antimalarial drug resistance: lessons for policy makers. Acta Trop 94: 269-280.

18. Pizzi E, Frontali C (2001) Low-complexity regions in Plasmodium falciparum proteins. Genome Res 11: 218-229.

19. Shendure J, Ji H (2008) Next-generation DNA sequencing. Nat Biotechnol 26: 1135-1145.

20. Mitra RD, Church GM (1999) In situ localized amplification and contact replication of many individual DNA molecules. Nucleic Acids Res 27: e34.

21. Drmanac R, Drmanac S, Chui G, Diaz R, Hou A, et al. (2002) Sequencing by hybridization (SBH): advantages, achievements, and opportunities. Adv Biochem Eng Biotechnol 77: 75-101.

22. Lagerqvist J, Zwolak M, Di Ventra M (2006) Fast DNA sequencing via transverse electronic transport. Nano Lett 6: 779-782.

23. Cao Y, Rui B, Wellems DL, Li M, Chen B, et al. (2013) Identification of piggyBac-mediated insertions in Plasmodium berghei by next generation sequencing. Malar J 12: 287.

24. Auer PL, Johnsen JM, Johnson AD, Logsdon BA, Lange LA, et al. (2012) Imputation of exome sequence variants into population- based samples and blood-cell-trait-associated loci in African Americans: NHLBI GO Exome Sequencing Project. Am J Hum Genet 91: 794-808.

25. Van Tyne D, Tan Y, Daily JP, Kamiza S, Seydel K, et al. (2014) Plasmodium falciparum gene expression measured directly from tissue during human infection. Genome Med 6: 110. 